\section{耍 Heighten Science \\ P U B L I C I T I O N S Corporation \\ ISSN \\ 2575-0143}

\title{
An observational study of the occurrence of anxiety, depression and self-reported quality of life 2 years after myocardial infarction
}

\author{
Catrin Henriksson ${ }^{1}$, Mona-Lisa Wernroth ${ }^{2}$ and Christina \\ Christersson ${ }^{3 *}$
}

${ }^{1}$ Clinical Lecturer, Department of Medical Sciences, Uppsala University, 75185 Uppsala, Sweden ${ }^{2}$ Bio-Statistician. PhD Student, Uppsala Clinical Research Center, Dag Hammarskjölds väg 14B, 75237 Uppsala, Sweden

${ }^{3}$ Department of Medical Sciences, Cardiology, Uppsala University, 75185 Uppsala, Sweden

\begin{abstract}
*Address for Correspondence: Catrin Henriksson, RN, PhD. Clinical Lecturer, Department of Medical Sciences, Uppsala University, 75185 Uppsala, Sweden, Tel: +46 (0) 703360886 ;

Email: catrin.henriksson@medsci.uu.se

Submitted: 26 September 2018

Approved: 16 October 2018

Published: 17 October 2018

Copyright: ๑ 2018 Henriksson C, et al. This is an open access article distributed under the Creative Commons Attribution License, which permits unrestricted use, distribution, and reproduction in any medium, provided the original work is properly cited
\end{abstract}

Keywords: Myocardial infarction; Quality of life; Anxiety and depression

(A) Check for updates

\section{Abstract}

Background: Patients with myocardial infarction (MI) often experience anxiety, depression and poor quality of life (QoL) compared with a normative population. Mood disturbances and QoL have been extensively investigated, but only a few studies have examined the long-term effects of MI on these complex phenomena.

Aims: To examine the levels and associated predictors of anxiety, depression, and QoL in patients 2 years after MI.

Methods: This was a single center, observational study of patients with MI ( $n=377,22 \%$ women, median age 66 years). Two years after Ml (2012-2014), the patients were asked to answer the Hospital Anxiety and Depression Scale (HADS) and EuroQol 5-dimension (EQ-5D-3L) questionnaires.

Results: Most patients experienced neither anxiety (87\%, 95\% confidence interval [CI]: $83-90 \%$ ) nor depression (94\%, 95\% Cl: 92-97\%) 2 years post-MI. Elderly patients experienced more depression than younger patients $(p=0.003)$ and women had higher anxiety levels than men $(p=0.009)$.

Most patients had "no problems" with any of the EQ-5D-3L dimensions (72-98\%), but $48 \%$ (95\% Cl: $43 \%$ $53 \%$ ) self-reported at least "some problems" with pain/discomfort. In a multiple logistic regression model (EQ$5 D-3 L)$ higher age $(p<0.001)$ and female sex $(p<0.001)$ were associated with more pain/discomfort. Female sex $(p=0.047)$ and prior MI $(p=0.038)$ were associated with anxiety/depression. History of heart failure was associated with worse mobility $(p=0.005)$ and problems with usual activities $(p=0.006)$. The median total health status of the patients (EQ-VAS) was 78 (95\% Cl: 75-80).

\section{Introduction}

Coronary heart disease (CHD) is the leading cause of disability worldwide [1] and in Europe 20\% of all deaths can be attributed to CHD [2].

Both anxiety and depression have previously been shown to be predictors of CHD [3-5]. Moreover, anxiety and depression are known to increase cardiac mortality [6-8].

Patients with myocardial infarction (MI) experience higher levels of anxiety than the general population [9], and there is growing evidence that higher levels of anxiety increase the risk of severe cardiac complications [10], recurrent events [10], and rehospitalizations post-MI [11].

The prevalence of depression in patients with MI is high compared with the general 
population $[4,6]$. In fact, up to two thirds of the patients with MI had mild depression during hospitalization [6]. Factors that increase the risk of CHD in depressed patients are enhanced platelet activation [12], endothelial dysfunction [13], inflammation [4], and non-adherence to lifestyle changes $[4,6,14]$. These factors are particularly important to consider in secondary prevention planning, especially the risk of nonadherence to behavior changes and poor medical compliance.

Patients with a MI experience worse quality of life (QoL) [15] within the first year of the event compared with the normative population [16]. Several factors influence QoL, including age, sex, hypertension, diabetes mellitus, prior MI and heart failure (HF) $[17,18]$; however, non-cardiovascular factors, such as anxiety [17] and depression $[17,19,20]$, also negatively impact QoL.

Mood disturbances and QoL in patients with MI have been extensively evaluated $[6,18,21,22]$, but few investigations have looked at the long-term effects of MI, especially in relation to both anxiety, depression and QoL. Therefore, this study aimed to examine the level and associated predictors of anxiety and depression, as well as patients' self-reported QoL 2 years after a MI.

\section{Methods}

\section{Design}

A descriptive and comparative design was adopted using two questionnaires.

\section{Data collection and characteristics}

This is a sub-study of the REBUS (The RElevance of Biomarkers for future risk of thromboembolic events in unselected post-myocardial infarction patients) trial [23,]. Briefly, unselected patients with both non-ST elevation (NSTEMI) and ST elevation (STEMI) MI, treated strictly according to guideline recommendations (e.g., patients underwent percutaneous coronary intervention and echocardiography with evaluation of left ventricular ejection fraction (LVEF) when indicated) were included in this observational study and followed for 2 years between 2012 and 2014 . Regarding medical treatment for the myocardial infarction all patients in the study were treated according to guidelines recommendations with a high prescription rate of antithrombotic treatment and statins during the whole study period. Information about medical history and current diseases (e.g., hypertension, diabetes, previous MI, heart failure) was collected at baseline.

During the 2-year follow-up, 14 patients died and 27 were excluded from the 2-year outpatient visit (the decision to exclude patients came from either the patients themselves or the principle investigator). However, the remaining patients who attended the 2-year outpatient visit agreed to complete the Hospital Anxiety and Depression Scale (HADS) ( $=376)$ and the EuroQol 5-dimension (EQ-5D-3L) questionnaires $(\mathrm{N}=377)$.

Process: At the end of the 2-year follow-up, a research nurse (who was not a member of the research team) asked the patients if they were willing to complete the HADS and EQ-5D-3L questionnaires. The patients were left alone in a quiet room and instructed on how to answer the two questionnaires, which took about 10-15 minutes to complete. Immediately after completion, the research nurse returned to the room and at this time the patients had the opportunity to ask the nurse questions about the questionnaires (e.g., if the respondents had difficulty answering or wanted clarification).

Instruments: Swedish versions of the HADS and EQ-5D-3L questionnaires were used. Both questionnaires have been tested for validity and reliability [24,25]. The questionnaires were coded, but not anonymized. 
HADS: The HADS consists of 14 items: the anxiety (HADS-A) and depression (HADS-D) subscales each with 7 items. Each item has a four-point response category regarding severity (0-3). Higher rates mean severe symptoms; 0-7=normal (no presence of anxiety/depression), 8-10= borderline abnormal (suggestive presence of anxiety/depression) and $\geq 11=$ abnormal (probable presence of anxiety/depression).

The patients were asked to respond to each item based on their perceived state over the past week.

Anxiety and depression were calculated according to Zigmond \& Snaith [26]. The scores were calculated separately for anxiety and depression and the maximum score for each subscale was 21 . Missing items were imputed by the participant's subscale mean if at least half of the items were answered [26].

EQ-5D-3L: QoL was assessed by the EQ-5D-3L. The questionnaire contains five dimensions of health-related QoL: mobility, self-care, usual activities, pain/discomfort, and anxiety/depression. For each of the five dimensions (EQ-index), there are three scoring levels: no problems, some problems, and extreme problems. To assess the patient's total health status, the questionnaire also includes a vertical visual analogue scale (EQ-VAS) with endpoint values ranging from 100 (Best imaginable health state) to 0 (Worst imaginable health state). The patients were asked to indicate the number on the scale that best described their perceived total health state. All the answers included the patients' self-reported QoL during the past week.

\section{Statistical analysis}

The results are presented as numbers and percentages, median, mean values and standard deviations (SD) as appropriate. The proportion (with $95 \%$ confidence intervals [CIs]) of patients with a HADS score $\geq 8$ and the proportion of patients with problems (some or extreme problems) in the EQ-5D-3L were reported. HADS, EQ-5D-3L and EQ-VAS levels were compared between groups using the Kruskal Wallis test and the Mann-Whitney U test. In addition, EQ-5D-3L and EQ-VAS were stratified by age and sex and compared with the general population [28].

Binary logistic regression was used to identify variables associated with problems (some or extreme problems) in the different dimensions in the EQ-5D-3L 2 years after index MI. The variables in this logistic regression included age, sex, hypertension, diabetes, prior MI, prior heart failure, STEMI at index MI, percutaneous coronary intervention (PCI) treatment and left ventricular ejection fraction (LVEF) $<0.45$. Multivariable models, including all variables simultaneously, were estimated. Odds ratios (ORs) with 95\% CIs are reported.

Spearman's rank order correlation coefficient was calculated to determine the association between the HADS, EQ-5D-3L anxiety/depression and EQ-VAS.

Missing HADS depression items were imputed for six patients and missing HADS anxiety items were imputed for eight patients.

All statistical tests were two-tailed and performed using a significance level of 0.05. No adjustments for multiple tests are reported. Analyses were performed in SAS version 9.4 (SAS Institute Inc. Cary, NC, USA).

Ethics: The study was approved by the local ethical committee (Uppsala Sweden) and followed the regulations of the Helsinki declaration (DNR 2009/210).

\section{Results}

The study population consisted of patients with a median age of 66 years (range $39-95$ years), 83 (22\%) patients were women and 294 (78\%) men (Table 1). The MI diagnosis was further sub-divided into NSTEMI $(n=199,53 \%)$ and STEMI $(n=178$, $47 \%$ ). Of the 377 patients included in the study, 306 (81\%) underwent PCI. 
HADS: We found that most patients experienced no anxiety (87\%, 95\% CI: 83-90\%, $\mathrm{n}=328$ ) or depression (94\%, 95\% CI: 92-97\%, n=355) 2 years after a MI. Thirty-two patients (9\%) experienced "suggestive presence of anxiety" and 11 patients (3\%) "Suggestive presence of depression". Only 16 patients (4\%) scored probable presence of anxiety and 10 patients (3\%) had scores equivalent to depression.

The median value of the summarized anxiety and depression scores was 2.0 in both dimensions and the mean values were $3.5(\mathrm{SD}=3.4)$ for anxiety and $2.5(\mathrm{SD}=2.7)$ for depression.

Elderly patients had worse depression scores $(\mathrm{p}<0.003)$ and female patients had higher scores on anxiety $(\mathrm{p}<0.009)($ Table 2$)$.

Feelings of tension or wound up were experienced "occasionally" in $32 \%$ of the patients and $22 \%$ did not enjoy things quite so much as before. Detailed information on each question is listed in table 3.

EQ-5D-3L: Most patients had "no problems" with any of the mobility dimensions (73\%, 95\% CI: 68-78\%, $\mathrm{n}=358$ ), self-care (98\%, 95\% CI: 96-99\%, $\mathrm{n}=368)$, usual activities (87\% , 95\% CI: 84-94\%, $\mathrm{n}=330$ ) or anxiety/depression (72\%, 95\% CI: 67-77\%, n=272), but nearly half of the patients ( $48 \%, 95 \% \mathrm{CI}: 43-53 \%, \mathrm{n}=182$ ) experienced at least "some problems" with pain/discomfort.

In multivariable analyses (Figure 1) age was only associated with problems in the dimension of pain/discomfort (per 10 years, $\mathrm{OR}=1.53, \mathrm{p}<0.001$ ). Women experienced more problems with pain/discomfort $(\mathrm{OR}=0.33, \mathrm{p}<0.001)$ and anxiety/depression $(\mathrm{OR}=0.58, \mathrm{p}=0.047)$ than men. Prior MI was associated with more anxiety/depression $(\mathrm{OR}=1.97, \mathrm{p}=0.038)$ and prior heart failure was associated with worse mobility $(\mathrm{OR}=4.14, \mathrm{p}=0.005)$ and usual activities $(\mathrm{OR}=4.65, \mathrm{p}=0.006)$.

The proportion of patients with some or extreme problems in the EQ-5D-3L dimensions were compared with the general population [28] (Figure 2). Problems with mobility were more common in the study population than in the general population.

The patients' total median health status (EQ-VAS) was 78 (95\% CI: 75-80) and the mean value was $74(\mathrm{SD}=18)$. Patients $>70$ years $(\mathrm{p}<0.001)$ and those with prior MI $(p=0.009)$ had worse EQ-VAS, but no sex differences were detected $(p=0.29)$. Other associated predictors are presented in Table 4 .

In Figure 3 the study populations' EQ-VAS was compared with that of the general population [28] as a function of age and sex. Younger people had better total health status compared with the elderly, regardless of sex.

Correlations were observed between the HADS and the EQ-5D-3L dimensions anxiety and depression and EQ-VAS (Table 5).

\begin{tabular}{|c|c|}
\hline Table 1: Baseline characteristics in the REBUS trial (N=377). & Total N=377 \\
\hline Variable & $66(39-95)$ \\
\hline Age, median (range), years & $83(22)$ \\
\hline Women, N (\%) & $200(53)$ \\
\hline Baseline characteristics (at index event) & $56(15)$ \\
\hline Hypertension, N (\%) & $65(17)$ \\
\hline Diabetes, N (\%) & $24(7)$ \\
\hline Prior MI, N (\%) & $199(53) / 178(47)$ \\
\hline Prior heart failure, N (\%) & $306(81)$ \\
\hline Procedures during hospitalization & $95(25)$ \\
\hline PCI, N (\%) & \\
\hline LVEF $<0.45, N(\%)$ & \\
\hline
\end{tabular}


Table 2: The distribution of anxiety and depression (HADS) and associated variables, $\mathrm{N}=376$.

\begin{tabular}{|c|c|c|c|c|c|c|c|}
\hline & & HADS & Anxiety & & HADS & Depression & \\
\hline & $\mathbf{N}$ & Mean & SD & P-value & Mean & SD & P-value \\
\hline Age (years) & & & & 0.09 & & & 0.003 \\
\hline $38-59$ & 97 & 3.78 & 3.94 & & 2.23 & 2.72 & \\
\hline $60-69$ & 152 & 3.06 & 3.20 & & 2.33 & 2.61 & \\
\hline $70-79$ & 88 & 3.45 & 3 & & 2.54 & 2.71 & \\
\hline $80-95$ & 39 & 4.31 & 3.18 & & 3.44 & 2.42 & \\
\hline Sex & & & & 0.009 & & & 0.29 \\
\hline Women & 83 & 4.17 & 3.40 & & 2.81 & 2.89 & \\
\hline Men & 293 & 3.27 & 3.35 & & 2.37 & 2.58 & \\
\hline Hypertension & & & & 0.71 & & & 0.85 \\
\hline Yes & 199 & 3.39 & 3.10 & & 2.38 & 2.44 & \\
\hline No & 177 & 3.56 & 3.67 & & 2.57 & 2.89 & \\
\hline Diabetes & & & & 0.91 & & & 0.18 \\
\hline Yes & 56 & 3.39 & 3.03 & & 2.54 & 2.11 & \\
\hline No & 320 & 3.48 & 3.43 & & 2.46 & 2.75 & \\
\hline Prior MI & & & & 0.21 & & & 0.13 \\
\hline Yes & 65 & 3.85 & 3.38 & & 2.91 & 2.77 & \\
\hline No & 311 & 3.39 & 3.37 & & 2.38 & 2.63 & \\
\hline Heart failure & & & & 0.51 & & & 0.45 \\
\hline Yes & 24 & 3 & 3.02 & & 2.83 & 2.78 & \\
\hline No & 352 & 3.50 & 3.40 & & 2.44 & 2.65 & \\
\hline STEMI & & & & 0.95 & & & 0.28 \\
\hline Yes & 178 & 3.49 & 3.45 & & 2.57 & 2.69 & \\
\hline No & 198 & 3.45 & 3.32 & & 2.38 & 2.63 & \\
\hline $\mathrm{PCl}$ & & & & 0.009 & & & 0.38 \\
\hline Yes & 306 & 3.67 & 3.43 & & 2.52 & 2.70 & \\
\hline No & 70 & 2.60 & 2.98 & & 2.26 & 2.45 & \\
\hline LVEF $<0.45$ & & & & 0.95 & & & 0.89 \\
\hline Yes & 95 & 3.40 & 3.34 & & 2.51 & 2.81 & \\
\hline No & 268 & 3.47 & 3.41 & & 2.48 & 2.63 & \\
\hline
\end{tabular}

$\mathrm{MI}=$ Myocardial infarction; NSTEMI=Non ST-elevation myocardial infarction; STEMI=ST-elevation myocardial infarction; $\mathrm{PCl}=$ Percutaneous Coronary Intervention; LV-EF=Left ventricular Ejection Fraction. LVEF was missing in $4 \%$ regarding to not needed in clinic; MannWhitney U test or Kruskal Wallis were used; SD=Standard deviation. SD=Standard deviation.

Table 3: Distribution of answers, HADS ( $\mathrm{N}=376)$.

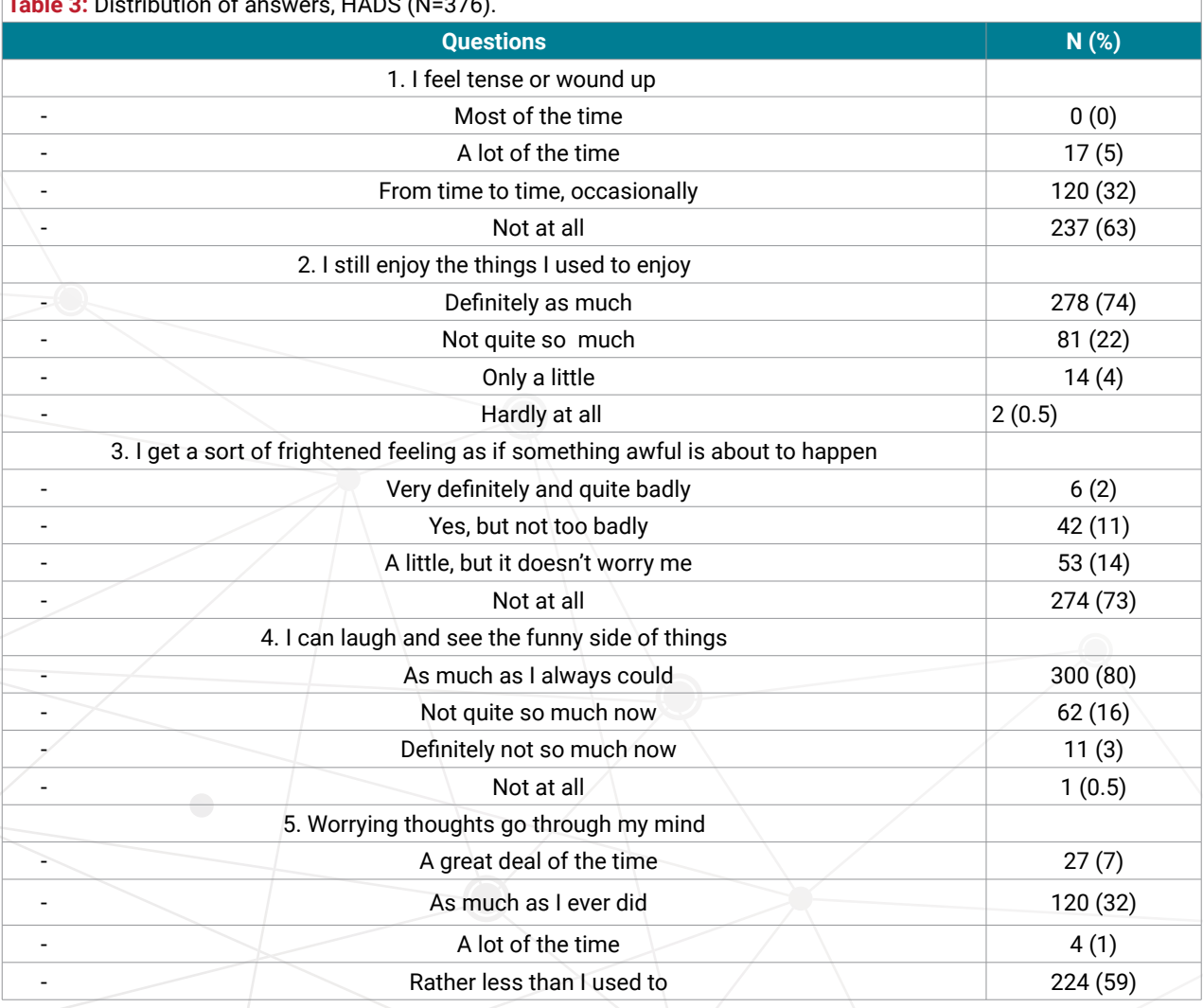




\begin{tabular}{|c|c|c|}
\hline \multicolumn{3}{|c|}{ 6. I feel cheerful } \\
\hline- & Not at all & $0 / 0$ \\
\hline- & Sometimes & $56(15)$ \\
\hline- & Not often & $11(3)$ \\
\hline- & Most of the time & $309(82)$ \\
\hline \multicolumn{3}{|c|}{ 7. I can sit at ease and feel relaxed } \\
\hline- & Definitely & $202(54)$ \\
\hline- & Usually & $152(40)$ \\
\hline- & Not Often & $20(5)$ \\
\hline- & Not at all & $2(0.5)$ \\
\hline \multicolumn{3}{|c|}{ 8. I feel as if I am slowed down } \\
\hline- & Nearly all the time & $6(2)$ \\
\hline- & Very often & $25(7)$ \\
\hline- & Sometimes & $241(64)$ \\
\hline- & Not at all & $103(27)$ \\
\hline \multicolumn{3}{|c|}{ 9. I get a sort of frightened feeling like "butterflies" in the stomach } \\
\hline- & As much as I ever did & $257(68)$ \\
\hline- & Rather less than I used to & $99(26)$ \\
\hline- & Definitely less than I used to & $16(4)$ \\
\hline- & Hardly at all & $1(0.3)$ \\
\hline \multicolumn{3}{|c|}{ 13. I get sudden feelings of panic } \\
\hline- & Very often indeed & $1(0.5)$ \\
\hline- & Quite often & $16(4)$ \\
\hline- & Not very often & $91(24)$ \\
\hline- & Not at all & $265(70)$ \\
\hline \multicolumn{3}{|c|}{ 14. I can enjoy a good book or radio/TV program } \\
\hline- & Often & $311(83)$ \\
\hline- & Sometimes & $56(15)$ \\
\hline- & Not often & $4(1)$ \\
\hline- & Very seldom & $2(0.5)$ \\
\hline
\end{tabular}

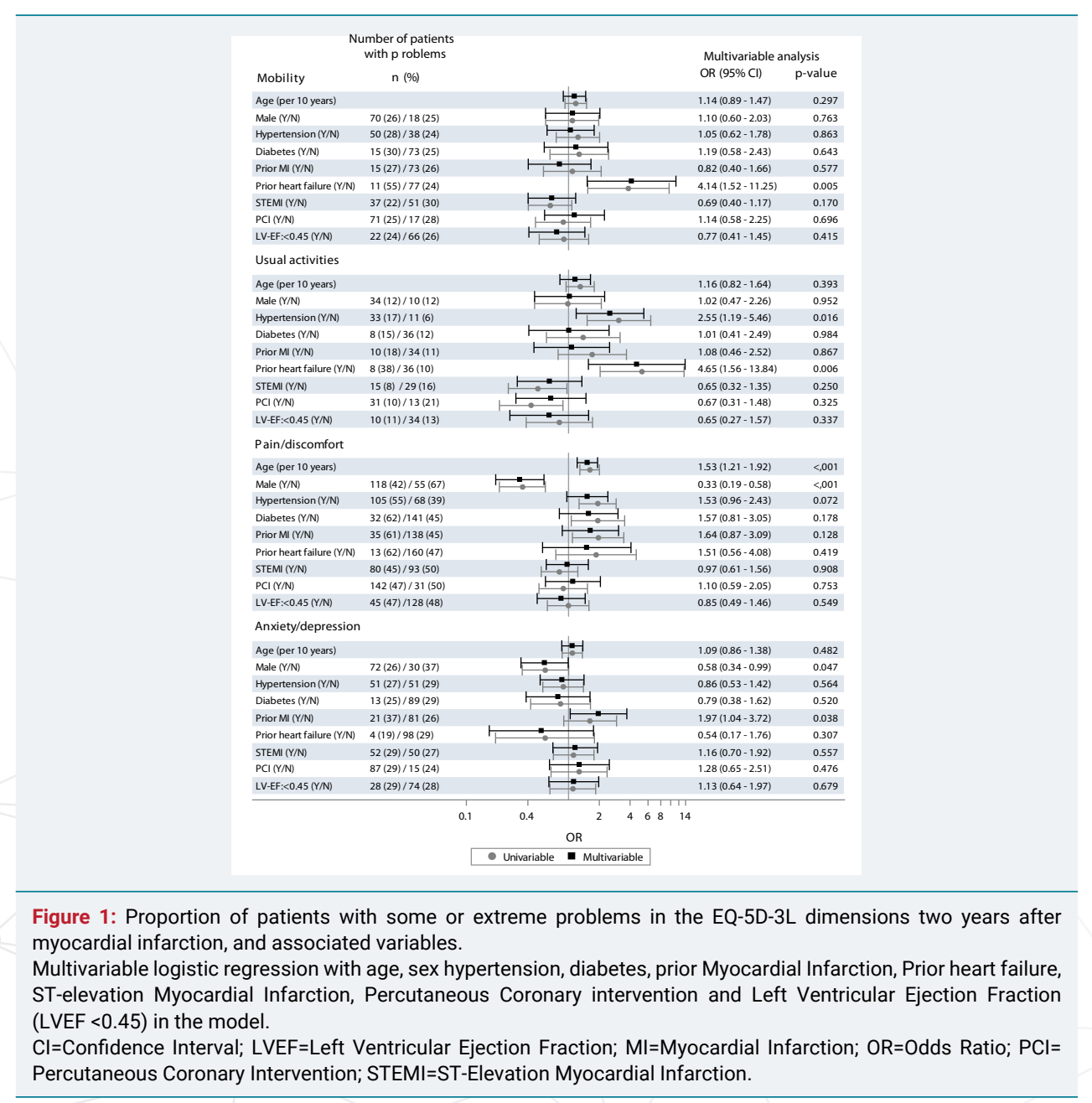



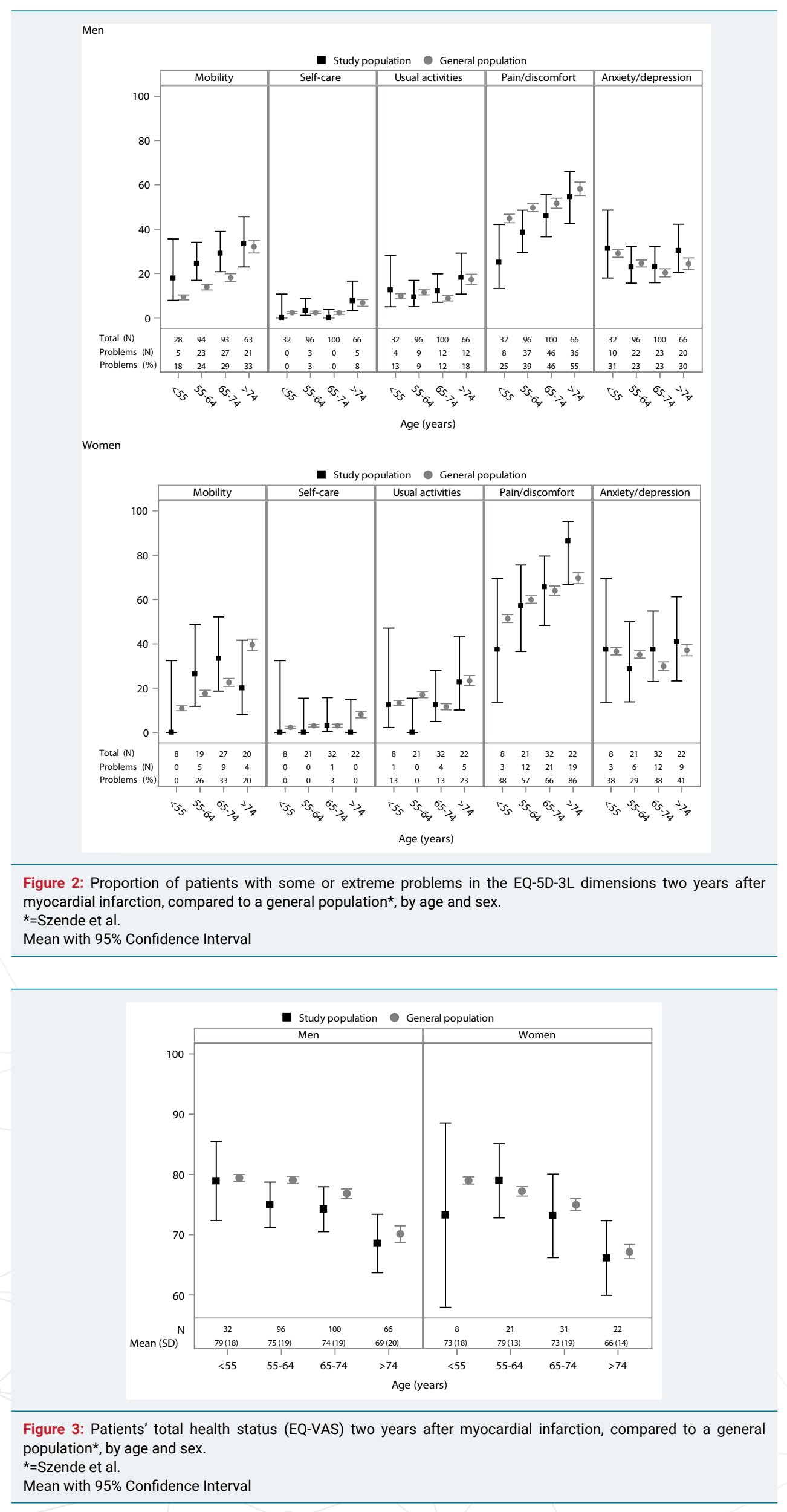
Table 4: Total health status (EQ-VAS) by baseline characteristics.

\begin{tabular}{|c|c|c|c|c|c|}
\hline & $\mathbf{N}$ & Mean & Median & SD & P-value \\
\hline Age (years) & & & & & $<0.001$ \\
\hline $38-59$ & 97 & 77.0 & 80 & 18.4 & \\
\hline $60-69$ & 151 & 74.5 & 80 & 18.7 & \\
\hline $70-79$ & 88 & 71.7 & 75 & 18.0 & \\
\hline $80-95$ & 40 & 65.0 & 69 & 16.6 & \\
\hline Sex & & & & & 0.36 \\
\hline Women & 82 & 72.8 & 75 & 16.7 & \\
\hline Men & 294 & 73.7 & 80 & 19.0 & \\
\hline Hypertension & & & & & 0.008 \\
\hline Yes & 199 & 71.3 & 75 & 18.6 & \\
\hline No & 177 & 75.9 & 80 & 18.1 & \\
\hline Diabetes & & & & & 0.020 \\
\hline Yes & 56 & 69.8 & 71 & 16.2 & \\
\hline No & 320 & 74.1 & 80 & 18.8 & \\
\hline Prior MI & & & & & 0.009 \\
\hline Yes & 65 & 68.6 & 70 & 18.1 & \\
\hline No & 311 & 74.5 & 80 & 18.4 & \\
\hline Heart failure & & & & & 0.039 \\
\hline Yes & 24 & 66.6 & 70 & 19.3 & \\
\hline No & 352 & 74.0 & 80 & 18.4 & \\
\hline STEMI & & & & & 0.37 \\
\hline Yes & 178 & 74.8 & 80 & 17.0 & \\
\hline No & 198 & 72.4 & 76 & 19.7 & \\
\hline $\mathrm{PCl}$ & & & & & 0.20 \\
\hline Yes & 305 & 74.2 & 80 & 18.1 & \\
\hline No & 71 & 70.5 & 75 & 20.0 & \\
\hline LV-EF $<0.45$ & & & & & 0.81 \\
\hline Yes & 95 & 73.6 & 78 & 18.0 & \\
\hline No & 268 & 73.9 & 79 & 18.8 & \\
\hline
\end{tabular}

MI=Myocardial infarction; NSTEMI=Non ST-elevation myocardial infarction; STEMI=ST-elevation myocardial infarction; $\mathrm{PCl}=$ Percutaneous Coronary Intervention. LV-EF=Left ventricular Ejection Fraction. LVEF was missing in $4 \%$ regarding to not needed in clinic; MannWhitney U test or Kruskal Wallis were used; SD=Standard deviation. SD=Standard deviation.

Table 5: Correlation between HADS and EQ-5D-3L (Anxiety/depression and EQ-VAS).

\begin{tabular}{|c|c|}
\hline \multicolumn{1}{|c|}{ Correlation between } & $\begin{array}{c}\text { Correlation estimate } \\
(\mathbf{9 5 \%} \text { Confidence interval) }\end{array}$ \\
\hline HADS anxiety and EQ-5D-3L anxiety/depression & $0.57(0.49-0.63)^{\star}$ \\
\hline HADS depression and EQ-5D-3L anxiety/depression & $0.47(0.39-0.55)^{\star}$ \\
\hline HADS anxiety and EQ-5D-3L VAS & $-0.93(-0.48--0.30)^{\star}$ \\
\hline HADS depression and EQ-5D-3L VAS & $-0.50(-0.58--0.42)^{\star}$ \\
\hline $\begin{array}{l}\text { Spearman's rank-order correlation } \\
\text { * }<0.001\end{array}$ \\
\hline
\end{tabular}

\section{Discussion}

Two years after a MI, experiences of anxiety and depression were normalized in our patient population. QoL was comparable with that of the general population [28], except for worse mobility in the study population.

Elderly patients and patients of the female sex had more problems with pain/ discomfort. Moreover, female patients experienced more anxiety than male patients.

Only a small proportion of the patients in this long-term follow-up experienced anxiety, depression, or both, which is in line with research showing that feelings of anxiety after a MI seem to decrease over time [29]. However, a Swedish study [30] showed that, whereas QoL (EQ-5D) after cardiac arrest improved over time, anxiety and depression (HADS) did not.

The probable explanation as to why patients with MI had few symptoms of anxiety and depression and a QoL similar to the general population 2 years after the event might be related to a time factor, but also that many individuals after a life-threatening 
event appreciate everyday things more and are grateful for being alive. However, it is important to inform patients about the fact that mood disturbances often dissipate with time.

The most frequent problem in the EQ-5D dimensions was pain/discomfort, which is similar to findings reported for the general population [28]. In Sweden, a large number of patients undergo PCI [31] and most of those patients present with no remaining symptoms. Therefore, the proportion of patients who reported problems with pain/ discomfort probably documented pain unrelated to the heart. The higher scores of pain/discomfort in the elderly and female patients might explain the increased symptoms of depression and poorer QoL in these groups.

Other studies [8,9] confirm our results regarding women's higher levels of anxiety and some studies have also reported worse depression and QoL in women [17,18,20,21]. The small differences in sex are probably a result of equally treated patients.

Prior MI was related to worse anxiety/depression in the EQ-5D-3L dimension but not in the HADS. Despite the correlations between the questionnaires, this result reflect some differences. EQ-5D-3L is a simpler way to measure anxiety/depression in comparison with the HADS. If the patients felt anxious or depressed and indicated "some" or "extreme" problems in the EQ-5D-3L, they were interpreted as anxious or depressed. In the HADS questionnaire individual item scores are summed to produce a reported score that must be above 7 to suggest the presence of a mood disorder.

The low frequency of mood disturbances and the relatively high QoL 2 years after a MI are better than expected findings. Despite the small number of patients who rated anxiety and depression, it is important to highlight this patient group. These patients who experience anxiety and depression are at higher risk of complications $[4,10,32$,] and mortality [6-8]. Furthermore, patients with depression are less likely to stop smoking $[6,33]$ and be physically active $[6,33]$. Therefore, health care providers must give more time and effort in these patients.

\section{Strengths and limitations}

The study has some limitations. First, because of the rather small sample size and because the patients were recruited from only one hospital, the results should be viewed considering these shortcomings. The study only measured anxiety, depression and QoL on one occasion as opposed to several occasions over time. We do not have information of how many patients initiated medications for anxiety and depression during follow up before answering the questionnaires which were distributed at the last study visit.

To take part in the study the patients had to understand the Swedish language. Patients were excluded if they did not have the capacity to complete the questionnaires.

One strength was that the two questionnaires were easy to complete, taking only about 10 minutes in total.

No comparisons were performed for the general population and HADS because of difficulties to find a comparable age-related population. Finally, no multivariate models in HADS were available because of the small number of patients reporting anxiety or depression.

The EQ-5D-3L is a general questionnaire and not disease-specific. It measures all types of pain and not only pain related to the heart. Questionnaires related specifically to patients with CHD are available [34-36], but these often focus on physical symptoms or conditions. A strength of the present study was that age and sex distribution in the study population was comparable to the national SWEDEHEART registry [31]. 
Other strengths are that the questionnaires have been tested for validity and reliability $[24,25,37,38]$, are easy to administer and understand and can be completed simply and quickly. The questionnaires were not anonymous because of the eventual need to contact patients if they were suffering from severe anxiety or depression. Further strengths of the study were the small number of responsible research nurses and that they were available if parts of the questionnaires were ambiguous or difficult to understand.

\section{Clinical implications}

Health care providers must give more attention to patients with mood disturbances and work continually to improve the support process, as well as to ask patients on a routine basis about their anxiety, depression and QoL.

A professional counseling team should be available and, when needed, patients should be offered psychosocial support. It is also important to inform patients that mood disturbances are common within the first year after a MI event but that such disturbances often become less intense with time.

\section{Acknowledgements}

We are grateful to the research nurses at the Department of Cardiology, Uppsala, University.

\section{Financial support}

The REBUS study was supported by grants from Erik, Karin and Gösta Selanders foundation, Uppsala, Sweden and the Society of health care professionals in cardiology, Sweden.

\section{References}

1. Murray CJ, Vos T, Lozano R, Naghavi M, Flaxman AD, et al. Disability-adjusted life years (DALYs) for 291 diseases and injuries in 21 regions, 1990-2010: a systematic analysis for the Global Burden of Disease Study 2010. Lancet. 2012; 380: 2197-2223. Ref.: https://goo.gl/bnu2pf

2. Townsend $\mathrm{N}$, Wilson $\mathrm{L}$, Bhatnagar $P$, Wickramasinghe $K$, Rayner $M$, et al. Cardiovascular disease in Europe: epidemiological update 2016. Eur Heart J. 2016; 37: 3232-3245. Ref.: https://goo.gl/od7AUP

3. Kubzansky LD, Kawachi I. Going to the heart of the matter: do negative emotions cause coronary heart disease? J Psychosom Res. 2000; 48: 323-337. Ref.: https://goo.gl/gg64vi

4. Lett HS, Blumenthal JA, Babyak MA, Sherwood A, Strauman T, et al. Depression as a risk factor for coronary artery disease: evidence, mechanisms, and treatment. Psychosom Med. 2004; 66: 305-315. Ref.: https://goo.gl/EyfNV5

5. Roest AM, Zuidersma $M$, de Jonge $P$. Myocardial infarction and generalised anxiety disorder: 10-year follow-up. Br J Psychiatry. 2012; 200: 324-329. Ref.: https://goo.gl/SrFvCK

6. Hare DL, Toukhsati SR, Johansson P, Jaarsma T. Depression and cardiovascular disease: a clinical review. Eur Heart J. 2014; 35: 1365-1372. Ref.: https://goo.gl/9KzBpZ

7. Lichtman JH, Froelicher ES, Blumenthal JA, Carney RM, Doering LV, et al. Depression as a risk factor for poor prognosis among patients with acute coronary syndrome: systematic review and recommendations: a scientific statement from the American Heart Association. Circulation. 2014; 129: 1350-1369. Ref.: https://goo.gl/VHNSgv

8. Watkins LL, Koch GG, Sherwood A, Blumenthal JA, Davidson JR, et al. Association of anxiety and depression with all-cause mortality in individuals with coronary heart disease. J Am Heart Assoc. 2013; 2: e000068. Ref.: https://goo.gl/jVtsXg

9. Moser DK, Dracup K, McKinley S, Yamasaki K, Kim CJ, et al. An international perspective on gender differences in anxiety early after acute myocardial infarction. Psychosom Med. 2003; 65: 511-516. Ref.: https://goo.gl/qauiKu

10. Moser DK, Riegel B, McKinley S, Doering LV, An K, et al. Impact of anxiety and perceived control on in-hospital complications after acute myocardial infarction. Psychosom Med. 2007; 69: 10-16. Ref.: https://goo.gl/Qub3TH 
11. Strik JJ, Denollet J, Lousberg R, Honig A. Comparing symptoms of depression and anxiety as predictors of cardiac events and increased health care consumption after myocardial infarction. $J$ Am Coll Cardiol. 2003; 42: 1801-1807. Ref.: https://goo.gl/PDgyRX

12. von Kanel R. Platelet hyperactivity in clinical depression and the beneficial effect of antidepressant drug treatment: how strong is the evidence? Acta Psychiatr Scand. 2004; 110: 163-177. Ref.: https://goo.gl/44cFce

13. Sherwood A, Hinderliter AL, Watkins LL, Waugh RA, Blumenthal JA. Impaired endothelial function in coronary heart disease patients with depressive symptomatology. J Am Coll Cardiol. 2005; 46: 656659. Ref.: https://goo.gl/2jcL24

14. Miller NH. Adherence behavior in the prevention and treatment of cardiovascular disease. $J$ Cardiopulm Rehabil Prev. 2012; 32: 63-70. Ref.: https://goo.gl/cKAyFo

15. Simpson E, Pilote L. Quality of life after acute myocardial infarction: a systematic review. Can J Cardiol. 2003; 19: 507-511. Ref.: https://goo.gl/R22HAL

16. Mollon L, Bhattacharjee S. Health related quality of life among myocardial infarction survivors in the United States: a propensity score matched analysis. Health Qual Life Outcomes. 2017; 15: 235. Ref.: https://goo.gl/MgDJvQ

17. Kang K, Gholizadeh L, Inglis SC, Han HR Correlates of health-related quality of life in patients with myocardial infarction: A literature review. Int J Nurs Stud. 2017; 73: 1-16. Ref.: https://goo.gl/dZiYWB

18. Perers E, From Attebring M, Caidahl K, Herlitz J, Karlsson T, et al. Low risk is associated with poorer quality of life than high risk following acute coronary syndrome. Coron Artery Dis. 2006; 17: 501-510. Ref.: https://goo.gl/BT1fcX

19. de Jonge $P$, Spijkerman TA, van den Brink RH, Ormel J. Depression after myocardial infarction is a risk factor for declining health related quality of life and increased disability and cardiac complaints at 12 months. Heart. 2006; 92: 32-39. Ref.: https://goo.gl/c1sYra

20. Parashar S, Rumsfeld JS, Spertus JA, Reid KJ, Wenger NK. et al. Time course of depression and outcome of myocardial infarction. Arch Intern Med. 2006; 166: 2035-2043. Ref.: https://goo.gl/X6cX47

21. Norris CM, Hegadoren K, Pilote L. Depression symptoms have a greater impact on the 1-year healthrelated quality of life outcomes of women post-myocardial infarction compared to men. Eur $J$ Cardiovasc Nurs. 2007; 6: 92-98. Ref.: https://goo.gl/aWuh72

22. van Beek MH, Mingels M, Voshaar RC, van Balkom AJ, Lappenschaar M, et al. One-year follow up of cardiac anxiety after a myocardial infarction: a latent class analysis. J Psychosom Res. 2012; 73: 362-368. Ref.: https://goo.gl/UgFQuW

23. Christersson C, Lindahl B, Berglund L, Siegbahn A, Oldgren J. et al. The utility of coagulation activity for prediction of risk of mortality and cardiovascular events in guideline-treated myocardial infarction patients. Ups J Med Sci. 2017; 122: 224-233. Ref.: https://goo.gl/2oULPV

24. Bjelland I, Dahl AA, Haug TT, Neckelmann D. The validity of the Hospital Anxiety and Depression Scale. An updated literature review. J Psychosom Res. 2002; 52: 69-77. Ref.: https://goo.gl/g2enya

25. Ellis JJ, Eagle KA, Kline-Rogers EM, Erickson SR. Validation of the EQ-5D in patients with a history of acute coronary syndrome. Curr Med Res Opin. 2005; 21: 1209-1216. Ref.: https://goo.gl/uuLHza

26. Zigmond AS, Snaith RP. The hospital anxiety and depression scale. Acta Psychiatr Scand. 1983; 67: 361-370. Ref.: https://goo.gl/x9XgCS

27. Bell ML, Fairclough DL, Fiero MH, Butow PN. Handling missing items in the Hospital Anxiety and Depression Scale (HADS): a simulation study. BMC Res Notes. 2016; 9: 479. Ref.: https://goo.gl/4crmX9

28. Szende A, Janssen B, Cabasés JM, EuroQol G. Self-reported population health: an international perspective based on EQ-5D (2014 ed.) 2014; Dordrecht: Springer. Ref.: https://goo.gl/B3sMHy

29. Hanssen TA, Nordrehaug JE, Eide GE, Bjelland I, Rokne B. Anxiety and depression after acute myocardial infarction: an 18-month follow-up study with repeated measures and comparison with a reference population. Eur J Cardiovasc Prev Rehabil. 2009; 16: 651-659. Ref.: https://goo.gl/ZjjoFp

30. Larsson IM, Wallin E, Rubertsson S, Kristofferzon ML. Health-related quality of life improves during the first six months after cardiac arrest and hypothermia treatment. Resuscitation. 2014; 85: 215220. Ref.: https://goo.gl/7FiF6e

31. SWEDEHEART Annual report. 2015. 2015; Ref.: https://goo.gl/vQVrdG 
32. Frasure-Smith $N$, Lespérance $F$, Talajic $M$. The impact of negative emotions on prognosis following myocardial infarction: is it more than depression? Health Psychol. 1995; 14: 388-398. Ref.: https://goo.gl/MiognK

33. Myers V, Gerber Y, Benyamini Y, Goldbourt U, Drory Y. Post-myocardial infarction depression: increased hospital admissions and reduced adoption of secondary prevention measures--a longitudinal study. J Psychosom Res. 2012; 72: 5-10. Ref.: https://goo.gl/apxVqu

34. Lampe FC, Whincup PH, Wannamethee SG, Ebrahim S, Walker M, et al. Chest pain on questionnaire and prediction of major ischaemic heart disease events in men. Eur Heart J. 1998; 19: 63-73. Ref.: https://goo.gl/ihKgk7

35. Spertus JA, Jones $\mathrm{P}$, McDonell M, Fan V, Fihn SD. Health status predicts long-term outcome in outpatients with coronary disease. Circulation, 106. 2002; 43-49. Ref.: https://goo.gl/8RVqG5

36. Spertus JA, Winder JA, Dewhurst TA, Deyo RA, Prodzinski J, et al. Development and evaluation of the Seattle Angina Questionnaire: a new functional status measure for coronary artery disease. J Am Coll Cardiol. 1995; 25: 333-341. Ref.: https://goo.gl/JxhnB1

37. Lisspers J, Nygren A, Söderman E. Hospital Anxiety and Depression Scale (HAD): some psychometric data for a Swedish sample. Acta Psychiatr Scand. 1997; 96: 281-286. Ref.: https://goo.gl/to5wCG

38. Schweikert B, Hahmann H, Leidl R. Validation of the EuroQol questionnaire in cardiac rehabilitation. Heart. 2006; 92: 62-67. Ref.: https://goo.gl/gg4tTv 